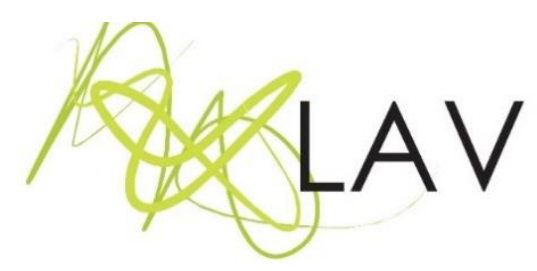

\title{
Experiencias y registros en escuelas rurales de Chiloé, Patagonia Chilena:
}

Educando en libertad

\author{
Experiences and records in rural schools of Chiloé, Chilean Patagonia: Educating in \\ freedom
}

Sergio Trabucco Zeran ${ }^{i}$

Escuela de Periodismo, Instituto de la Comunicación e Imagen, Universidad de Chile

\begin{abstract}
Resumen
A través de dibujos, cartas, fotografías y juegos, se realizaron ciclos de talleres en escuelas rurales unidocentes y multigrados en la Isla Grande y en la Isla Quinchao del Archipiélago de Chiloé, en la Patagonia Chilena, lo que resultó, por un lado, en la confección de una bitácora de la experiencia, y por otro, en ciclos de talleres a cargo de artistas de Chile, Brasil y Argentina. Se trata de proyectos en construcción (vivos) en tanto registros de experiencias de memoria y territorio que nacen en un contexto de crisis de la educación pública en Chile, iniciada en 2006 por los estudiantes escolares, presentándose como una necesidad por parte del autor, quien además es profesor en la Universidad de Chile pero que no está restringido a un territorio, por mirarse, descubrirse y entender el lugar que habitamos en una constante contraposición escuela/campo, poniendo en tensión la concepción de ciudad y modernidad desde una concepción autobiográfica e identitaria.
\end{abstract}

Palabras-claves: ruralidad, autobiografía, educación, registros, insularidad.

\begin{abstract}
Through drawings, letters, photographs and games, workshops were held in one-teacher and multi-grade rural schools on Isla Grande and Isla Quinchao in the Chiloé Archipelago, in Chilean Patagonia, which resulted, on the one hand, in the preparation of a log of experience, and, on the other hand, in cycles of workshops by artists from Chile, Brazil and Argentina. These are (living) projects under construction as records of experiences on memory and territory, born in a context of crisis in the public education in Chile, started in 2006 by school students, presented as a need by the author, who is also a professor at the University of Chile and who is not restricted to a territory, to understanding the place we inhabit in a constant school/field contrast, putting into tension the conception of city and modernity from an autobiographical and identity perpective.
\end{abstract}

Keywords: rurality, autobiography, education, records, insularity. 


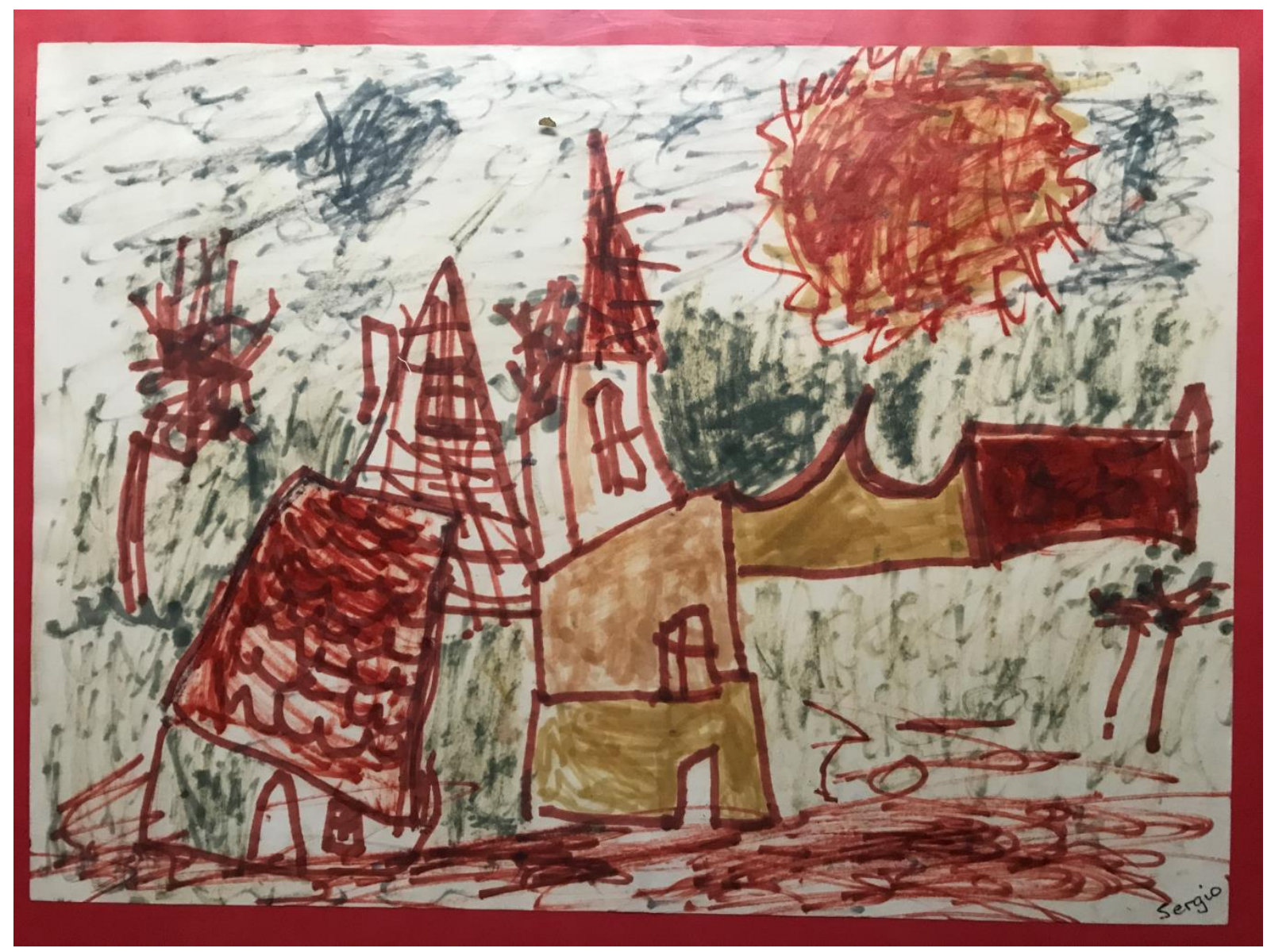

Figura 01. Home and house: I also live in the sun. Sergio Trabucco Zeran, Santiago de Chile, 1987 (durante la dictadura cívico militar en Chile)

A mis padres, por educarme en libertad.

A Nana Albano, por guiarme en el camino de educar con libertad.

\section{Raíces del desarraigo}

Hacía tiempo que rondaba en mi mente la idea de volver al extremo sur de la Patagonia chilena, a Puerto Natales, específicamente, y de esta forma también volver a mis raíces, ya que mi bisabuela había llegado al extremo sur de Chile en la década de los años veinte proveniente de Siria y mi bisabuelo de Palestina. Fue en Puerto Natales donde nació mi abuela y mi madre, quien se convertiría en la primera de la familia en estudiar en la universidad. Yo soy la segunda generación. Puerto Natales está muy lejos y es muy difícil llegar ahí, por lo que descartamos la idea y nos quedamos en Chiloé donde en 2013 construí mi casa. 
Junto a mi casa, también inicié un trabajo de mediación y circulación artística-cultural en distintas islas del Archipiélago de Chiloé, un conjunto de más de cuarenta islas y donde sólo hay educación pública y rural. Lo que realmente había iniciado era un sueño, y también algo que me hiciera sentido de vida.

Para ese entonces estaba convencido de que el regreso a mis raíces debía tener un vínculo fuerte con el fomento al arte en la educación, ya que en Chile las escuelas abren muy poco espacio para la creatividad, para la expresión de los estudiantes y para que niños, niñas y jóvenes se conecten con sus microhistorias, construyendo así un relato personal que conforma uno generacional.

Partí con una alianza con el Teatro Nacional Chileno, que depende de la Facultad de Artes de la Universidad de Chile - y donde trabajé por nueve años- Ilevamos obras de teatro a las escuelas más alejadas, las más pospuestas y las más vulnerables, por lo que, junto a las presentaciones, hicimos talleres con las comunidades.

Era hermoso ver cómo niños muy pequeños de escuelas unidocentes y multigrado, que nunca habían visto una obra de teatro, llegaban con sus propias sillas al gimnasio de la Escuela Rural de Manao. El proyecto fue creciendo, así como la casa se fue terminando, y para ese entonces yo ya tenía un compromiso con la Escuela Rural de Manao a través de un taller de autobiografía para los estudiantes de último año. Sentía que los niños que viven en el campo y más aun los que habitan las islas, le estaban dando la espalda a sus raíces y no estaban mirando el lugar donde vivían. Era el verano de 2015 y Marlen Cárdenas, la Directora de la Escuela, ya me había dado la bienvenida a su comunidad educativa. Siempre digo que vivo en Chiloé, pero la verdad es que vivo en Santiago y desde ahí viajo por Chile para trabajar en escuelas y liceos haciéndole talleres a niños y niñas, activando los elementos que ellos eligen como identitarios, hablando de ellos, de sus familias, sus historias y sus lugares. Soy un profesor de la Universidad de Chile que no se limita a su universidad, sino que ha hecho de su país su universidad.

\section{Un juego muy serio}

La autobiografía y el testimonio son temas que me han acompañado e interesado durante mis 36 años de vida. Desde muy pequeño mi hermana y yo tomamos conciencia e hicimos nuestra la historia de mis padres, quienes se conocieron en el Movimiento de Izquierda Revolucionario, MIR, luchando contra la dictadura de Pinochet. Siempre supimos acerca de la tortura de mi padre y del exilio de ambos en Venezuela. También supimos que no querían que naciéramos en el exilio, sino que, en Chile, y quizás eso contribuyó a sentir un compromiso muy fuerte por el desarrollo del arte y la cultura. Es así como - a través del

Revista Digital do LAV - Santa Maria - vol. 11, n. 2, p. 245 - 258 - mai./ago. 2018 ISSN 1983 - 7348 http://dx.doi.org/10.5902/1983734832833907 
testimonio- me empezaron a interesar nuestros orígenes y las raíces, así como el deber testimoniar y el derecho a recordar.

Es así como le propuse a la Directora de la Escuela Rural de Manao un taller de representaciones titulado "Del texto a la escena: un viaje de voces personales", bajo la idea de que fuese el propio Centro de Padres y Apoderados de la Escuela, quienes presentaran este proyecto a un Fondo Nacional de Desarrollo Regional. Este proyecto buscó, a través de la generación de experiencias significativas vinculadas a la educación artística, que los estudiantes pudiesen dibujar, escribir y fotografías su entorno, permitiéndoles observar, bajo su propia interpretación, el lugar que habitan.

Las escuelas rurales tienen un rol muy importante en el desarrollo artístico de las comunidades, puesto que, debido a la falta de teatros y espacios para el desarrollo cultural, las escuelas son polos y los Centros de Padres y Apoderados son entidades vinculantes y convocantes, por lo que nuestro proyecto no me pertenecía a mí, era un proyecto de Manao.

Al poco tiempo de haber postulado, nos informaron que no habíamos quedado aceptados y que nuestro proyecto había quedado en lista de espera. Yo sentía que tenía un compromiso con la Escuela y que no podía decepcionar a los niños, quienes ya sabían del taller y los esperaban, por lo que lo inicié de manera autofinanciada. Un mes después la lista de espera corrió y nos dieron el fondo. El taller duró un año y medio (agosto 2016 a diciembre 2017) y fue una experiencia hermosa y muy significativa para todos. En definitiva, era un juego muy serio.

\section{Lo que dejan de ver cuando ya no están}

En la Escuela Rural de Manao la educación llega hasta octavo básico, luego de eso los estudiantes, proveniente de sectores rurales aledaños, deben irse a escuelas más grandes, predominantemente en la ciudad de Ancud y algunos de ellos internados. Este fenómeno de traslado obligatorio por continuidad de estudios escolares y de desarraigo en la etapa formativa fue determinante a la hora de pensar el proyecto "Del texto a la escena: un viaje de voces personales", en el que también participó el actor Tomás Henríquez con dinámicas teatrales; la periodista Paulina Ortega con el registro, recopilación y edición del material que iban produciendo los estudiantes en las sesiones del taller; y la diseñadora Carola Osorio en la confección a mano de la bitácora de la experiencia, un cuadernillo que reúne testimonios, experiencias, registros fotográficos y dibujos. Todos amigos que se sintieron convocados por este proyecto corazón, que poco después viviría en otras escuelas de otra isla en el Archipiélago de Chiloé.

Revista Digital do LAV - Santa Maria - vol. 11, n. 2, p. 245 - 258 - mai./ago. 2018 ISSN 1983 - 7348 http://dx.doi.org/10.5902/1983734832833907 
¿Qué dejan de ver cuando ya no están? Es una pregunta que me rondaba a la hora de pensar en el proyecto, pero también en mi madre que siendo muy pequeña se tuvo que ir desde Punta Arenas a Puerto Montt para estudiar en el Liceo de niñas. Al preguntarle por qué es tan aprensiva con mi hermana y conmigo ella me responde que es porque la mandaron siendo muy pequeña a estudiar sola y que eso la hizo ser como es.

Tomás, Paulina y yo viajamos una vez al mes a impartir los talleres. Es muy poco frecuente que en el invierno en la Patagonia Chilena saliera el sol, pues en todos, o la mayoría de nuestros talleres nos acompañó el sol, por lo que mis clases las hacía en el jardín de la Escuela Rural de Manao, un establecimiento que hace muy pocos años fue beneficiado con el proyecto de mejoramiento para escuelas y liceos públicos en Chiloé impulsado por el Gobierno de Chile y que robó mi corazón.

Nuestros talleres debían ser programados en el horario correspondiente a alguna clase. El mío topaba con inglés, por lo que los niños y niñas estaban felices de no tener esa clase y de alguna forma me hacían creer que esperaban mi taller. Cada vez que llegaba a la Escuela, veía cómo se agolpaban y asomaban por la ventana, decían "ahí viene" y sentía el ruido de las sillas y las mesas, no podía sentir el sonido de sus zapatos porque en Chiloé los niños se cubren los zapatos con lana, ya que afuera siempre hay barro y a las profesoras no les gusta que ensucien el piso.

En la Escuela Rural de Manao habían cuatro profesores jóvenes, a mí me gustaba que dos de ellos, Víctor y Fabián, me acompañaran en los talleres. Sentía que al igual que yo, ellos podían ser niños también, podían jugar y divertirse, además que conocían muy bien a los niños, sabían cómo tratarlos. Para Víctor y Fabián el taller que yo hacía les permitía conectarse con sus propias historias. Ellos me ayudaban a que los estudiantes mantuvieran la concentración. Uno de ellos era Jhon Barría quien presentaba una condición diferente a sus compañeros, por lo que inmediatamente me concentré en él. Pensé que a Jhon podría costarle más participar del taller, pero fue todo lo contrario. Cuando preguntaba quién quería hablar, él era el primero, quien había llevado la tarea, él levantaba de inmediato la mano, cuando preguntaba qué sentían o qué pensaban, era él el primero en opinar. Jhon quería hablar de él, no tenía vergüenza en hacerlo y sus compañeros lo escuchaban con atención. Para finales de 2016, y antes de las vacaciones de verano, felicité a Jhon por su desempeño, le envié una nota a su madre y le pedí que para el próximo año siguiera siendo el mejor de todos. Sin duda Jhon era distinto y al poco tiempo me di cuenta que la condición positiva de su condición diferente, era que no se inhibía, lo que ayudaba a la dinámica que yo quería lograr. Jhon esperaba el taller con ansias, se sentí orgulloso de vivir en el campo, solo con su madre, rodeado de naturaleza y junto a sus animales.

Revista Digital do LAV - Santa Maria - vol. 11, n. 2, p. 245 - 258 - mai./ago. 2018 ISSN 1983 - 7348 http://dx.doi.org/10.5902/1983734832833907 
Fue en la Escuela Rural de Manao cuando conocí a Paulo Freire. Como todo en mi vida yo sólo hacía sin saber que el modelo de cómo trabajaba correspondía a la metodología que él enseñaba. Eso me lo dijo Víctor y Fabián, ellos sí conocían de las teorías de Freire y me hacían ver que mi forma de enseñar era la que aparecía en el libro. Hasta ese minuto yo no lo había leído.

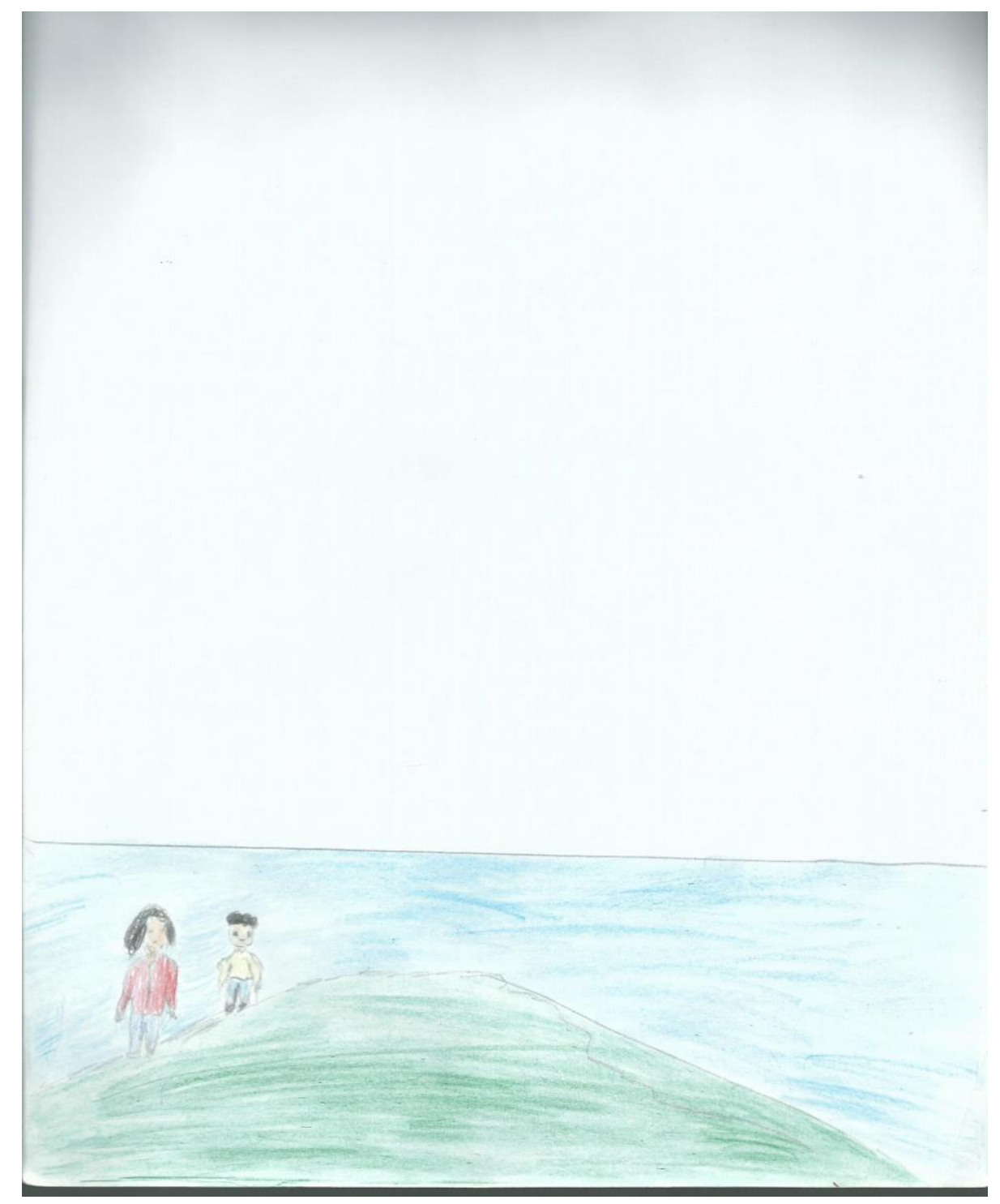

Figura 02. La madre de Jhon y Jhon. Estudiante: Jhon Álvarez, Escuela Rural de Manao, Isla Grande, Chiloé, 2017.

\section{The island to island project}

Esta experiencia me permitió ir, en mayo de 2017, a un congreso de Educación en Artes Visuales organizada por el Programa Europeo CREARTE, titulado "Creative Primary School Partnerships with Visual Artists" en Chipe, ocasión en la que puede hablar ante una audiencia de casi 200 profesores de arte, sobre el trabajo en la Escuela Rural de Manao.

Revista Digital do LAV - Santa Maria - vol. 11, n. 2, p. 245 - 258 - mai./ago. 2018 ISSN 1983 - 7348 http://dx.doi.org/10.5902/1983734832833907 
Era mi primera vez en un congreso internacional y yo sentía la responsabilidad de estar representando a los niños y niñas de Chiloé en una isla muy lejos a la de ellos. Terminada mi presentación, se me acercó una profesora con una idea fantástica, crear el proyecto Island to Island, conectando a las escuelas a través de arte postal.

Si bien la Escuela Rural de Manao está al norte de la Isla Grande de Chiloé, yo ya tenía experiencia de trabajo en otras islas, como la Isla de Quinchao. El mismo año que fui a Chipre, y pocos meses antes (marzo) realizamos, junto a la destacada pianista Clara Luz Cárdenas, quien además era la Decana de la Facultad de Artes de la Universidad de Chile y la Profesora Ximena Poo, académica del Instituto de la Comunicación e Imagen de la misma universidad, la inauguración del año escolar rural con un concierto de piano, el que titulamos "el concierto de piano en el lugar donde no había un piano". Esa experiencia fue hermosa, dado que hubo que trasladar un piano entre una escuela y otra, igual como si fuese una minga, festividad tradicional chilota en la que las comunidades tiran o trasladan por tierra y mar una casa. Lo mismo pasó con el piano, hubo que trasladarlo en un proceso igual de generoso y colaborativo como una minga.

Dentro del público asistente al concierto de piano, en el cual convocamos a las seis escuelas rurales unidocentes de la comuna de Curaco de Vélez (cuyo total de matrícula sumaban 26 niños aproximadamente) y las escuelas multigrado de Palqui y San Javier de la misma comuna, estaban los niños de la Escuela Rural Vista Hermosa, un lugar que había cautivado mi corazón y de cuya comunidad sentía un gran cariño y compromiso, dado que eran sólo cuatro niños, compuestos por una pareja de mellizos y los cuatro eran primos entre ellos. Con esa comunidad postulé y me gané un proyecto que me permitió invitarlos a la Universidad de Chile en octubre de 2017. Era la primera vez que salían de su isla, primera vez que volaban, primera vez que iban a I capital, primera vez que iban a la universidad, primera vez que veían edificios altos, primera vez que iban al teatro, al cine, al zoológico, era la primera vez de un sinfín de cosas que yo sentí, al redescubrirlas a través de la experiencia de ellos, también fueron mi primera vez. Para octubre de 2018 repetiremos el proyecto, el que creció, permitiendo ahora que tres escuelas rurales unidocentes (Vista Hermosa, Diañ y Chúllec) junto a la Escuela Rual de Manao viajen a Santiago. De cuatro niños que fueron en 2017, ahora serán 20.

Es así que gracias al trabajo con las Escuelas Rurales de Manao en la Isla Grande y la Escuela Rural Vista Hermosa en la Isla de Quinchao, pude ejecutar la idea que nació en Chipre, dándole vida entre agosto y diciembre de 2017 al proyecto Island to Island Project: Quinchao Manao Quinchao. Era arte postal con dibujos y textos de los niños y niñas de ambas comunidades. Yo dividía me tiempo entre una escuela y otra y hacía de cartero

Revista Digital do LAV - Santa Maria - vol. 11, n. 2, p. 245 - 258 - mai./ago. 2018 ISSN 1983 - 7348 http://dx.doi.org/10.5902/1983734832833907 
llevando la correspondencia entre islas y le pedí a la panadera de Manao que se convirtiera en el buzón donde dejaban las cartas que iban a Quinchao. De esta manera los niños podían escribir sobre el lugar donde vivían, conectándose con su cosmovisión, la naturaleza y los elementos que ellos sentían constituían sus identidades. Terminado el taller los niños del sector de Los Palquis donde se encuentra la Escuela Rural Vista Hermosa y la Escuela Rural Eduardo Frei Montalva en el sector de Palqui, quienes también participaron de la experiencia, viajaron a Manao, pudiendo conocer con quienes se enviaban las cartas.

Hoy, estamos trabajando un grupo interdisciplinar en el proyecto Island to Island Project: Manao Rapa Nui Manao, para el 2018 conectar la Isla Grande en el Archipiélago de Chiloé con Rapa Nui o Isla de Pascua.

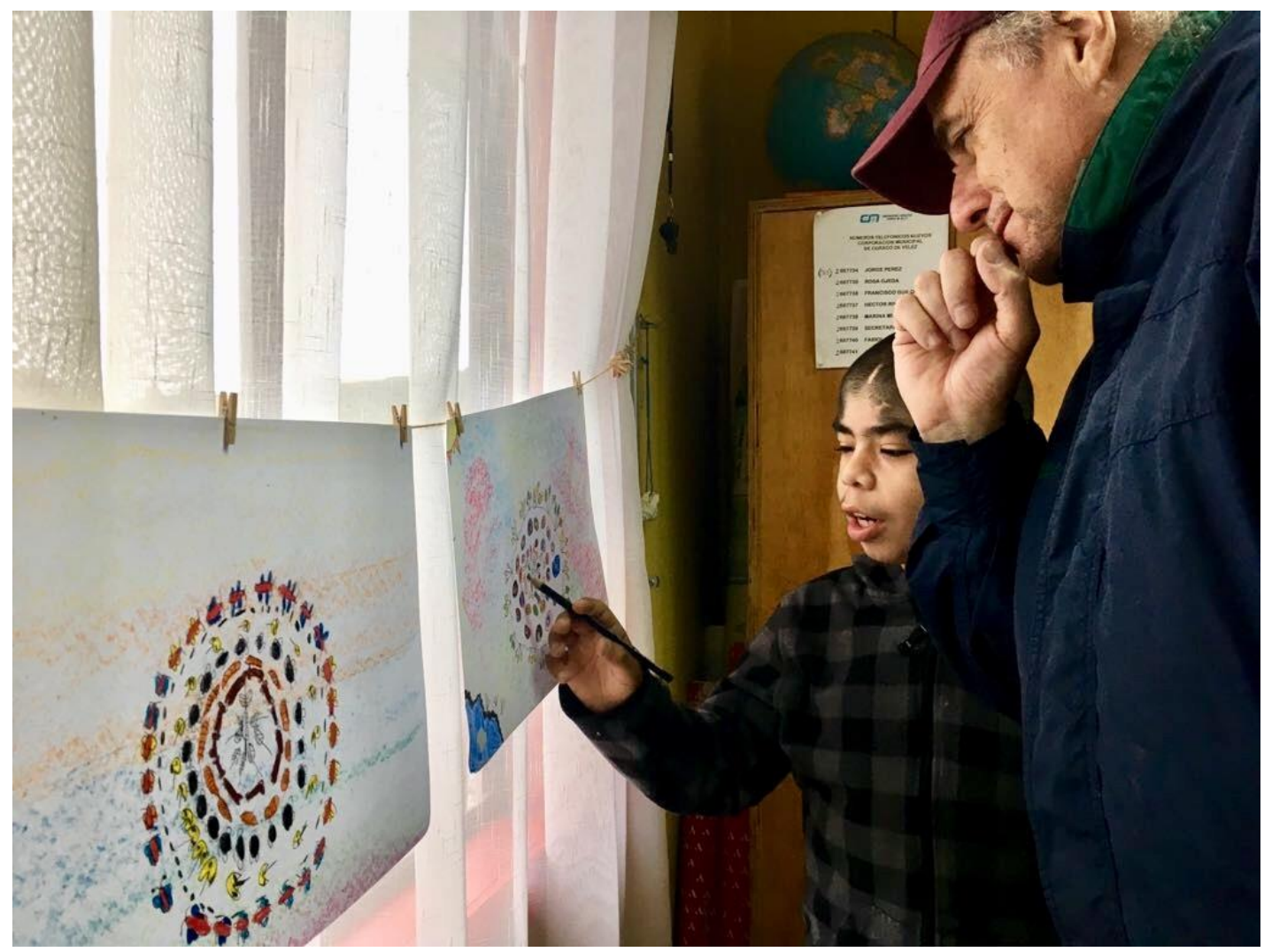

Figura 03. El académico del Departamento de Artes Visuales de la Facultad de Artes de la Universidad de Chile, Iñaki Uribarri en un taller en la Isla de Quinchao en el Archipiélago de Chiloé, marzo 2018.

\section{El Flautista de Hamelin}

Hace poco tiempo atrás, una muy querida amiga que ha participado activa y generosamente en los proyectos a los que la he convocado en las Escuelas de Chiloé, me dijo que yo era como el Flautista de Hamelin. Ella tiene razón, me siento como ese 
personaje que con su flauta mágica atrae y convoca. Su metáfora me lleva a pensar acerca de la flauta que utilizo para mi propósito, para ese propósito colectivo que tiene como fin invitar a artistas a las escuelas, transformarlas en lugares creativos. Es un sueño colectivo que se hace realidad cada vez que trabajamos, un equipo de profesores y artistas, con los niños y niñas de Chiloé, muy especialmente cuando llegamos a lugares donde ni el Estado llega, como lo es la Isla de Quinchao en Chiloé.

Es así como inventé un hito en la educación en el Archipiélago: la Inauguración del Año Escolar Rural en la comuna de Curaco de Vélez en la, cuya segunda versión del encuentro, en marzo de 2018 , contó con artistas chilenos, brasileños y argentinos. A diferencia de la primera versión, que fue un concierto de piano en un día, esta vez fueron cuatro, y además agregamos el componente internacional. Lo que ocurrió fue hermoso. Todo partió como un sueño, invitar a artistas sensibles y comprometidos y a expertas internacionales (en una mezcla de cariño, amistad y experiencia) para que trabajáramos juntos en la inauguración del año escolar rural con las seis escuelas rurales unidocentes que sentí y siento, merecen trabajo y atención.

Había algunos componentes de dificultad que incluí, a diferencia del año anterior, en este proyecto: el trabajo simultáneo con las seis escuelas rurales unidocentes, artistas en las escuelas y el trabajo de artistas que no se conocían y que tenían que trabajar con dos escuelas al mismo tiempo.

Este proyecto no es parte de mis "obligaciones académicas", es la realización de un sueño que es compartido, que se vuelve realidad. En este sueño participa la Universidad de Chile y el Ministerio de las Culturas, las Artes y el Patrimonio, pero también instituciones locales.

Lo único que yo quería era que los niños y niñas se pudiesen expresar, de que sus lugares de enseñanza y aprendizaje tuviesen un sentido creativo, pudiendo ser además un espacio de juego, de diversión, de expresión y sobre todo, de conexión con sus emociones. Ana Angélica Albano, académica de la UNICAMP en Brasil (o Nana como le decimos los amigos) fue invitada para hacer un taller de artes visuales en las escuelas rurales de Diañ y Chúllec con el artista visual y académico del Departamento de Artes Visuales de la Facultad de Artes de la Universidad de Chile, Iñaki Uribarri; Susana Salerno actriz Argentina fue invitada para realizar un taller de teatro con el académico del Departamento de Teatro de la Facultad de Artes, Igor Pacheco, en las escuelas de Vista Hermosa y Huyar Bajo; Ximena Poo, académica del Instituto de la Comunicación e Imagen junto a mí, impartimos el taller de autobiografía en la Escuela Rural Unidocente de Huenao. Héctor Sepúlveda, académico del Departamento de Música de la Facultad de Artes fue el encargado de inaugurar el año

Revista Digital do LAV - Santa Maria - vol. 11, n. 2, p. 245 - 258 - mai./ago. 2018 ISSN 1983 - 7348 http://dx.doi.org/10.5902/1983734832833907 
escolar rural junto a su guitarra, con un concierto en el Centro Cultural de Curaco de Vélez. Su generosidad permitió que visitara otras escuelas, las que se habían enterado de esta inauguración y que no eran parte del programa. Él supo entender la importancia de lo que estábamos haciendo y acudió, generosamente, a cada lugar al que fue llamado.

Dejamos que los talleres comenzaran. Los profesores invitados me hacían preguntas: ¿cómo era la escuela? ¿Cuántos niños había? ¿Cómo iban a hacer para que los de una escuela fueran a la otra? Yo sólo dejé que las cosas ocurrieran, que las personas que se habían comprometido con el proyecto hicieran lo que sabían tenían que hacer. Y eso ocurrió, las cosas fueron resultando, los talleres fueron resultando una experiencia hermosa para todos.

Pero lo que no tenía contemplado, era que las profesoras visitantes a la otra escuela, iban a pedir también hacer el taller en las de ellas: era lógico, pensé después, hay un sentido de pertenencia, orgullo y dedicación que sin duda se iba a imponer ante la experiencia y ellas, las profesoras, iban a querer guiar lo que ocurriera. $Y$ eso hicimos, los talleres se fueron moviendo y para la segunda sesión nos movimos.

Tampoco sabía muy bien qué iba a pasar con el taller que Nana y Susana iban a impartir esas tardes a las profesoras. Dejé que se conocieran, que no hubiese ningún pie forzado, nada premeditado, dejé que se abrieran a la improvisación y una vez más confié. Lo que ocurrió ahí fue lindo. Las profesoras necesitaban un espacio para conversar, para trabajar sus emociones, un espacio donde las escucharan.

Había escuchado a un experto decir que la interacción entre estudiantes era importante, por eso juntamos a las seis escuelas en tres talleres, para que los niños pudieron compartir con otros como ellos. El último día no sabíamos qué íbamos a hacer cuando todos, estudiantes y profesores se juntarán en una escuela, la de Tolquien. Cuando apareció la pelota nos dimos cuenta que ellos sólo querían jugar entre ellos. Los dejamos jugar sin intervenir demasiado. Y esa interacción entre comunidades resultó.

Este es un proyecto vivo, en desarrollo y en constante evolución, que dialoga con otras iniciativas culturales que llevo adelante. Esta iniciativa está marcada por el cariño, el respeto y un sentido de pertinencia territorial y fue posible gracias a la colaboración de un grupo de personas generosas de instituciones unidos por un solo propósito y que creemos en la necesidad de que el arte se instale como un motor para el fortalecimiento de la Educación Pública, de cara a la formación de ciudadanos más sensibles y emocionalmente más conectados

Revista Digital do LAV - Santa Maria - vol. 11, n. 2, p. 245 - 258 - mai./ago. 2018 ISSN 1983 - 7348 http://dx.doi.org/10.5902/1983734832833907 
Se trata de un sueño por proporcionar una ampliación cultural para los niños que viven "aislados". Esto es un proyecto personal, voluntario, que ha podido atraer a otros profesores que voluntariamente participan de este sueño, apoyado por la Universidad, el Ministerio, y otras instituciones, como la Corporación Municipal de Educación de Curaco de Vélez, entre otros.
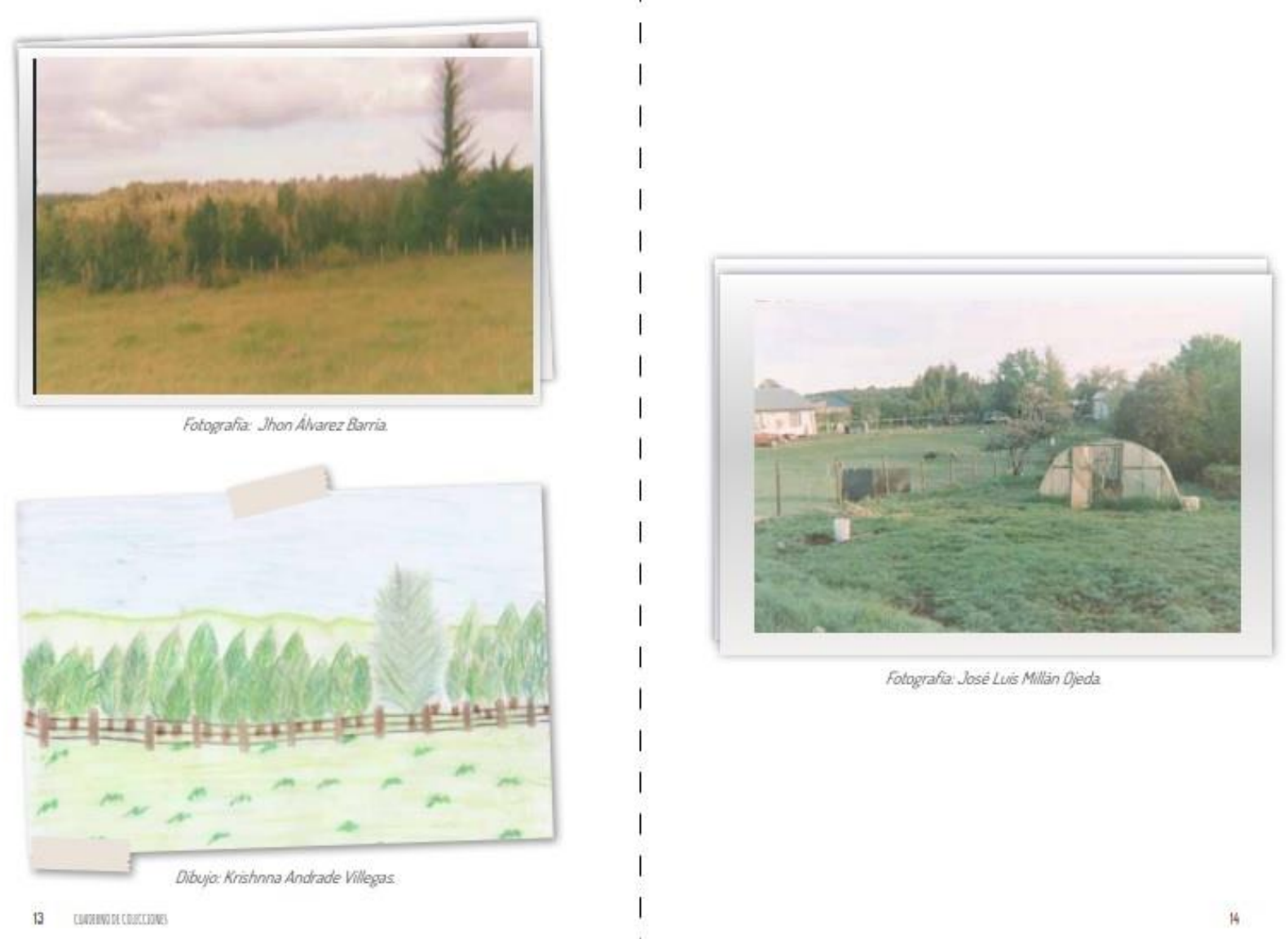

Fotografia: José Luis Mïin Ojeda

Figura 04. Bitácora de la experiencia, Manao Archipiélago de Chiloé, 2017.

\section{El derecho a testimoniar y el deber de recordar}

La experiencia en las Escuelas rurales de Chiloé son la prueba de que hay- entre los niños y niñas- un interés por verse, por mirarse, por reconocerse. Cuando pensé en el trabajo en la Escuela, pensé que lo único que los niños necesitan es tener la instancia para poder hacer vivir su autobiografía, para expresar su identidad y los rasgos que ellos eligen para la construcción de esa identidad.

Los niños tienen derecho a testimoniar, a saber y poder manifestarse. Así lo demostraron a través de las fotografías que tomaron, de los dibujos que hicieron, de las cartas que escribieron y de los objetos que recolectaron. Lo que a ellos les sucede es algo que importa, 
que trasciende, que resalta un Chile rural, campesino, que existe y que ellos tienen que permitirse expresar, conectándose con sus emociones.

Termino este proyecto con la sensación de que se supieron escuchar, de que se supieron ver, de que pudieron mirar y sentir este lugar del que quiero que se sientan orgullosos. Termino este taller confirmando que sí es posible dotar al aula de un sentido creativo, imaginativo, lúdico. Termino este viaje seguro de que los espacios de educación -superior y escolar- deben ser espacios de expresión, donde al profesor le importe qué es lo que los estudiantes piensan y sienten. Termino este recorrido eligiendo los textos, las fotografías y los dibujos de este grupo de niñas y niños como parte de mi propia identidad.

Finalmente pienso que si bien, soy profesor de la Universidad de Chile, no estoy restringido a la universidad, ya que mi universidad es Chile entero, ya que me siento un recolector de las historias de los niños y sus profesores en escuelas en todo el país, por donde transito con libertad con mi maletín imaginario para guardar sus historias como si tuviera el mal de Diógenes, ese que recolecta sin parar.

Estos proyectos son mis proyectos de vida. Empezó como la construcción de mi casa y terminó como un trabajo de cambio de procesos de enseñanza. Estos proyectos hablan de ampliar mundos, de transformar las escuelas en lugares de imaginación, creación y diversión. Yo soy un puente y me siento vivo cuando estoy en estos proyectos que están lejos de encontrar un fin.

\section{Referencias}

ACASO, M. Reduvolution. Hacer la revolución en la educación. Buenos Aires: Paidós, 2015.

ARFUCH, L. EI Espacio Biográfico: Dilemas de la Subjetividad Contemporánea, Fondo de Cultura Económica, Ciudad de México, 2002.

Memoria y Autobiografía: Exploraciones en los límites. Fondo de Cultura Económica, Ciudad de México, 2013.

SOUZA, E. C. Autobiografias, histórias de vida e formação: pesquisa ensino. Porto Alegre, RS, Brasil: Edipucrs, 2006.

FREIRE, P. Pedagogía del oprimido. Buenos Aires: Siglo XXI Editores, 2014.

Revista Digital do LAV - Santa Maria - vol. 11, n. 2, p. 245 - 258 - mai./ago. 2018 ISSN 1983 - 7348 http://dx.doi.org/10.5902/1983734832833907 
FREIRE, P. y SHOR, I. Miedo y osadía. La cotidianidad del docente que se arriesga a práctica. Buenos Aires: Siglo XXI Editores, 2014.

CANCLINI, N. G. Culturas híbridas. Estrategias para entrar y salir de la modernidad. Ciudad de México: Grijalbo,1990.

GONZÁLEZ, Y. y FEIXA, C. La construcción histórica de la juventud en América Latina. Santiago de Chile: Cuartopropio, 2013.

HALBWACHS, M. La memoria colectiva, Prensas Universitarias de Zaragoza, 2004.

HALL, S. y DU GAY, P. Cuestiones de Identidad. Madrid, España: Amorrortu Editores, 2011.

HERNANDEZ, F. Educación y Cultura Visual, Barcelona, España: Octaedro,2010.

JIMÉNEZ, L., AGUIRRE, I. y PIMENTEL, L. G. (Sin fecha) Educación artística, cultura y ciudadanía, Colección Metas Educativas 2021, Madrid, España: Editan Santillana y OEI, 2011.

LEJEUNE, P. EI Pacto Autobiográfico y otros estudios. Megazul-Endymion, 1975.

MARTINS, R. y TOURINHO, I. Educação da Cultura Visual: narrativas de ensino e pesquisa. Santa María, RS, Brasil: Ed. de UFSM, 2009.

PIPER, I.I y HEVIA, E. Espacio y Recuerdo: Archipiélago de Memorias en Santiago de Chile. Santiago de Chile: Ocho Libros, 2012.

RUBIA, G. Memoria, política y Pedagogía: Los caminos hacia la enseñanza del pasado reciente en Chile. Santiago de Chile: LOM, 2013.

SARLO, B. Escenas de la vida posmoderna. Intelectuales, arte y videocultura en la Argentina, Buenos Aires: Ariel, 1994.

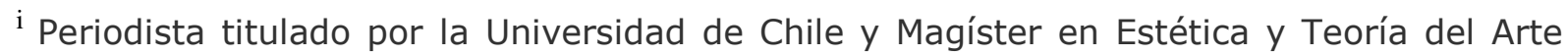
Contemporáneo por la Universidad Autónoma de Barcelona, España. Profesor de pregrado y postgrado de la Universidad de Chile, además de evaluador y jurado en concursos literarios del Ministerio de las Artes, las Culturas y el Patrimonio del Gobierno de Chile e integrante de la International Society For education Through Art - InSEA. Trabajo en gestión cultural, educación a través del arte e impartiendo talleres para niños y niñas de escuelas públicas en todo Chile.
}

Revista Digital do LAV - Santa Maria - vol. 11, n. 2, p. 245 - 258 - mai./ago. 2018 ISSN 1983 - 7348 http://dx.doi.org/10.5902/1983734832833907 
Como citar esse artigo:

ZERAN, Sergio Trabucco. Experiencias y registros en escuelas rurales de Chiloé, Patagonia Chilena: Educando en libertad. Revista Digital do LAV, Santa Maria: UFSM, v. 11, n. 2, p. 245-258, mai./ago. 2018. 